\title{
Formic acid aided hot water extraction of hemicellulose from European silver birch
}

\section{(Betula pendula) sawdust}

Werner Marcelo Goldmann ${ }^{\mathrm{a}, *}$, Juha Ahola ${ }^{\mathrm{a}}$, Marja Mikola ${ }^{\mathrm{a}}$, Juha Tanskanen ${ }^{\mathrm{a}}$

${ }^{a}$ Chemical Process Engineering, Faculty of Technology, University of Oulu, P.O. Box 4300, Oulu 90014, Finland

Keywords: Hemicellulose, Xylose, Furfural, Formic Acid, Hot Water Extraction

\section{Highlights}

- Hydrolysis of hemicellulose with low cellulose degradation was achieved

- Obtained a residual solid product low on hemicellulose and high on cellulose

- The lignin concentration in the extract fell below the detection limit of $3 \mathrm{~g} / \mathrm{L}$

\begin{abstract}
Hemicellulose has been extracted from birch (Betula pendula) sawdust by formic acid aided hot water extraction. The maximum amount of hemicellulose extracted was about $70 \mathrm{~mol} \%$ at $170{ }^{\circ} \mathrm{C}$ of the total hemicellulose content, measured as the combined yield of xylose and furfural. Lower temperatures (130 and $\left.140{ }^{\circ} \mathrm{C}\right)$ favored hemicellulose hydrolysis rather than cellulose hydrolysis, even though the total hemicellulose yield was less than at $170{ }^{\circ} \mathrm{C}$. It was found that formic acid greatly increased the hydrolysis of hemicellulose to xylose and furfural at the experimental temperatures. The amount of lignin in the extract remained below the detection limit of the analysis $(3 \mathrm{~g} / \mathrm{L})$ in all cases. Formic acid aided hot water extraction is a promising technique for extracting hemicellulose from woody biomass, while leaving a solid residue with low hemicellulose content, which can be delignified to culminate in the three main isolated lignocellulosic fractions: cellulose, hemicellulose, and lignin.
\end{abstract}

\section{Introduction}

Lignocellulosic feedstocks (LCFs) have gained research interest and industrial relevance due to their potential for production of fine chemicals (and their precursors) within the biorefinery concept (Budzinski \& Nitzsche. 2016). 
LCFs are mainly composed of cellulose, hemicellulose and lignin. Although cellulose is usually the main target for refining and has a currently high value in the pulp and paper industry, hemicellulose and lignin are also key components of LCFs. Simple polysaccharides (e.g. xylan) can be obtained from hemicellulose. These polysaccharides can be depolymerized into their simple sugar monomers, such as xylose (Dutta \& Chakraborty. 2015). The sugar monomers can then be further reacted into specialty chemicals like furfural (Wang et al. 2015) and xylitol (Yadav et al. 2012). Organosolv pulping has been used to remove hemicellulose and lignin from LCF's, using solvents such as ethanol (Xu et al. 2007), formic acid (Li et al. 2012), and acetic acid (Sahin \& Young. 2008). One alternative is to first reduce the hemicellulose content in the LCF before delignification.

A feasible pathway to isolate hemicellulose and consequently reduce the hemicellulose content in the initial LCF is by hot water extraction (Krogell et al. 2014). Typically, hot water extraction is done at temperatures above the normal boiling point of water, which allows for a better solubilization of the hemicellulose and depolymerization of polysaccharides (e.g. xylan to xylose) (Maurya et al. 2015). Factors such as temperature (Rissanen et al. 2016), time (Tunc \& van Heiningen. 2008), and chip size (Song et al. 2012) have been explored in hot water extraction. Krogell et al. (2013) have reported mass yields of $95 \%$ of total hemicellulose (75\% of total dissolved solids) with $170{ }^{\circ} \mathrm{C}$ hot water extraction for 2 hours of spruce with particle size $0.5-0.7 \mathrm{~mm}$, and $73 \%$ of total hemicellulose ( $63 \%$ of total dissolved solids) for particle size $8-12.5 \mathrm{~mm}$. These results were obtained with a liquid to wood ratio of about 11. Li et al. (2013) reported yields of $61.5 \mathrm{wt} \%$ of xylose and furfural in the hot-water-extracted liquor at $170{ }^{\circ} \mathrm{C}$ (particle size $27^{*} 1.8^{*} 1.2 \mathrm{~mm}$ ) for 1 hour. They reported that the amount of xylose and xylose-oligomers and xylose-polysacccharides in the liquor was $65 \mathrm{wt} \%$ of the total sugars, while the xylose monosaccharides were much less than $65 \mathrm{wt} \%$ of the total sugars, indicating a less effective hydrolysis of xylan to xylose than other carbohydrates.

Diluted sulfuric acid has been utilized for acid hydrolysis of hemicelluloses (Liu et al. 2012). Additionally, hydrolysis of wheat pulp in formic acid medium with the purpose of extracting glucose has been reported (Kupiainen et al. 2012). During formic-acid-aided hot water extraction, hemicellulose (namely xylan) is depolymerized into xylose, which is in turn dehydrated into furfural. Side-reactions occur within the 
xylose-furfural pathway, as well as degradation of furfural, where polymerization occurs and undesired water-insoluble humins are formed from xylose and furfural (Hu et al. 2012, Wang et al. 2015).There has been reports of pretreatment of corn stover with $4 \mathrm{~g} / \mathrm{L}$ of formic acid (Xu et al. 2009), and hemicellulose extraction from hardwood at 1 and $10 \mathrm{~g} / \mathrm{L}$ of formic acid (Tunc et al. 2014). Nevertheless, there is not extensive knowledge on the effect of higher concentration of formic acid on hot water extraction with the express purpose of extracting hemicellulose.

The objective of hot water extraction of hemicellulose is to remove as much hemicellulose from wood as possible. This is achieved by the hydrolysis of polysaccharides (hemicellulose) to smaller oligomers and the monosaccharide xylose (and its dehydration product, furfural). When the targets of the extraction are xylose and furfural, acid-catalyzed hydrolysis can benefit the extraction by allowing a more effective hydrolysis from polysaccharides to monosaccharides. Formic acid plays a role in decreasing the transition state energies of the hydrolysis reaction (Zhang et al. 2014). Additionally, formic acid has been reported to catalyze the dehydration reaction of xylose to furfural (Lamminpää et al. 2012). Moreover, dissolution of the lignin matrix by formic and acetic acids during pulping (Watkins et al. 2015) suggests that formic acid has a solvent effect, additional to its catalytic effect. Formic acid has also been shown to catalyze the hydrolysis of cellulose to glucose and HMF (Kupiainen et al. 2014).

The purpose of this work was to assess the effect of formic acid in hot water hemicellulose extraction with respect to the yield of the xylose and its dehydration product, furfural.

\section{Materials and methods}

\subsection{Sawdust and solvents}

Birch (Betula pendula) sawdust was obtained from a Finnish sawmill. The birch utilized for this study contained $33 \mathrm{wt} \%$ of hemicellulose, $38 \mathrm{wt} \%$ of cellulose, and $24 \mathrm{wt} \%$ of lignin, with about $4 \mathrm{wt} \%$ of extractives and about 1 wt\% of ash. Given that hemicellulose is mainly composed of pentose polysaccharides (Scheller \& Ulvskov. 2010), 
the hexose determination was deemed not crucial. Analytical grade (98-100 vol\%) formic acid and ultrapure water were utilized as solvents in the extractions.

\subsection{Sawdust analysis}

The sawdust analysis was carried out in duplicate. The moisture content of the samples was obtained by drying the samples in an oven at $105{ }^{\circ} \mathrm{C}$ to constant weight. The ash content was determined using the procedure described by Sluiter et al. (2008a). Wood samples ( $3 \mathrm{~g}$ ) were extracted with $150 \mathrm{~mL}$ of acetone for 4 hours by Soxhlet extraction to remove organic extractives (TAPPI T 280 pm-99. 1999). Extractive-free samples were utilized to determine lignin and holocellulose content. Klason lignin was determined after a two-step acid hydrolysis of the wood sample according to Sluiter et al. (2008b). Acid-soluble lignin was determined by UV-Vis spectroscopy from the hydrolysate obtained from the hydrolysis according to the procedure described by Erhman (1996). The amount of lignin is presented as a sum of acid-insoluble and acid-soluble lignin. Holocellulose was prepared from extractive-free samples, applying the procedure described by Rowell et al. (2005). The extractive-free sample (1.5 g), $48 \mathrm{~mL}$ distilled water, $0.3 \mathrm{~mL}$ acetic acid, and $0.75 \mathrm{~g}$ sodium chlorite were allowed to react in a $100 \mathrm{~mL}$ Erlenmeyer flask in a water bath $\left(70-75^{\circ} \mathrm{C}\right)$. After 60 minutes, $0.3 \mathrm{~mL}$ acetic acid and $0.75 \mathrm{~g} \mathrm{NaClO} 2$ were added. After each succeeding hour, $0.3 \mathrm{ml}$ acetic acid and $0.75 \mathrm{~g} \mathrm{NaClO}_{2}$ were added. After 5 hours, the flask was allowed to cool and the solid holocellulose was filtered. The solid residue was washed with distilled water until the yellowish color was removed. Finally, the solid was washed with acetone. The holocellulose was dried overnight in an oven at $105^{\circ} \mathrm{C}$, cooled in desiccator for an hour and weighed. The residual lignin content in holocellulose was determined by the above-mentioned methods. The $\alpha$-cellulose content was determined from the holocellulose, applying previously published procedures (Styarini et al. 2012, Tappi T203 cm-99. 2009, Yokoyama et al. 2002). Half a gram $(0.5 \mathrm{~g})$ of holocellulose and $25 \mathrm{ml}$ of $17.5 \% \mathrm{NaOH}$ were placed in a $250 \mathrm{~mL}$ beaker and stirred until the holocellulose was completely dispersed. The stirrer was then removed and washed with $5 \mathrm{~mL}$ of $17.5 \% \mathrm{NaOH}$ to make total reagent content in the beaker $30 \mathrm{~mL}$. The beaker was stirred thoroughly with a glass rod and placed in a water bath at $25^{\circ} \mathrm{C}$. After $30 \mathrm{~min}$ from the first addition of $\mathrm{NaOH}, 30 \mathrm{~mL}$ of distilled water was added to the suspension and stirred thoroughly with the glass rod. The flask was left in the bath for another 30 min (for a total 
of $60 \mathrm{~min}$ ), after which the suspension was stirred and filtered. The solid $\alpha$-cellulose was washed first with distilled water, then with $15 \mathrm{ml}$ of $10 \%$ Acetic acid, and finally with $400 \mathrm{ml}$ distilled water. The hemicellulose content was obtained by subtracting the $\alpha$-cellulose content from the holocellulose content.

\subsection{Extraction procedure}

The extractions were carried out in 40-mL zirconium reactors fitted with zirconium screw caps and fluoroelastomer O-rings. The preheating was done via a heating block with wall temperature between $300-400{ }^{\circ} \mathrm{C}$, where the bodies of the reactors were inside the heater while the top structures (the caps and the O-rings) remained above the heater walls (allowing the O-rings to remain within temperature specifications). Additionally, the contact with the heating block was only kept until the target temperature (in the range of $1-4$ minutes depending on the final temperature).

After preheating to the target temperature, the reactors were moved to a fluidized sand-bath at constant temperature. After the reaction time, the reactors were quenched in a water vessel to at least $35^{\circ} \mathrm{C}$ before being opened. A sample from the extract was taken with a conventional 3-mL syringe with a steel needle and subsequently filtered through a $0.45-\mu \mathrm{m}$ PTFE syringe filter. The filtrate was then diluted 1:7 $(200 \mu \mathrm{L}: 1.4 \mathrm{~mL})$ in ultrapure water and analyzed by HPLC.

The indicators of the extraction were the yield of xylose, furfural, glucose, HMF, and lignin in the liquid product, as well as the extraction yield ratio of the hemicellulose products to cellulose products. One of the objectives of the extraction was to keep the glucose, HMF, and lignin yields as low as possible in the liquid product, as only hemicellulose products (xylose, furfural) were desired in the liquid. The maximum amount of hemicellulose available was $33 \mathrm{wt} \%$ of the dry wood mass. In order to estimate the yield of hemicellulose, the molar mass of the xylan monomer unit was approximated by subtracting the molar mass of water from xylose to obtain the molar mass of a single xylan unit (i.e. $132.11 \mathrm{~g} / \mathrm{mol}$ ). This was under the assumption that the hemicellulose was composed of mostly large chains of xylan. Similarly, for cellulose, the molar mass of a single glucan unit was approximated 
$(162.14 \mathrm{~g} / \mathrm{mol})$ from the molar masses of glucose and water. The calculation of the molar yield percentage $\left(Y_{i}\right)$ was done according to the following equations (Eq. 1-4):

$$
\begin{aligned}
Y_{\text {xylose }}(\text { mol\% }) & =\frac{m_{\text {xylose }}(g)}{x_{\text {hemicellulose }} m_{\text {sawdust }}(g)} * 87.97 \\
Y_{\text {furfural }}(\text { mol } \%) & =\frac{m_{\text {furfural }}}{x_{\text {hemicellulose }} m_{\text {sawdust }}} * 137.49 \\
Y_{\text {glucose }}(\text { mol\% }) & =\frac{m_{\text {glucose }}}{x_{\text {cellulose }} \cdot m_{\text {sawdust }}} * 90.00 \\
Y_{\text {HMF }}(\text { mol } \%) & =\frac{m_{H M F}}{x_{\text {cellulose }} \cdot m_{\text {sawdust }}} * 128.57 \\
\text { Extraction Yield Ratio }(E Y R) & =\frac{Y_{\text {xylose }}+Y_{\text {furfural }}}{Y_{\text {glucose }}+Y_{\text {HMF }}}
\end{aligned}
$$

Where $m_{i}$ is the mass of compound $i$ obtained from the HPLC analysis, $m_{\text {sawdust }}$ is the mass of dry sawdust, and $x_{i}$ is the mass fraction of hemicellulose $(0.33)$ or cellulose $(0.38)$ in the birch dry sawdust. The constants were calculated based on the molar masses of the compounds and sugar units. Additionally, the extraction yield ratio was calculated as the ratio between of the combined yield of xylose and furfural to the combined yield of glucose and $\operatorname{HMF}$ (Eq. 5).

\subsection{HPLC analysis}

HPLC analysis was performed with an Agilent 1200 HPLC equipped with a Coregel 87 H3 column. The method used a $10 \mu \mathrm{L}$ injection volume, a flowrate of $0.8 \mathrm{~mL} / \mathrm{min}$ for 40 minutes at a column temperature of $60{ }^{\circ} \mathrm{C}$. The mobile phase was composed of $0.005 \mathrm{M} \mathrm{H}_{2} \mathrm{SO}_{4}$. The detectors utilized were Refractive Index Detector (RID) and Diode Array Detector (DAD). The DAD was set to $210 \mathrm{~nm}$ and $280 \mathrm{~nm}$ with $4 \mathrm{~nm}$ bandwidths; the reference wavelengths were $250 \mathrm{~nm}$ and $320 \mathrm{~nm}$ respectively with $100 \mathrm{~nm}$ bandwidths.

\subsection{Lignin analysis}


The lignin content in the liquid was estimated by UV-spectrophotometry. There are procedures described to analyze lignin content by UV spectrophotometry, such as measuring the absorbance at about 205 nm maximum (Ehrman. 1996) or at the $280 \mathrm{~nm}$ maximum (Hatfield \& Fukushima. 2005). However, it was found experimentally that both furfural and HMF have characteristic absorption spectra in the same range as lignin, thus making the determination challenging. The lignin content in the liquid was estimated using a Shimadzu 1800-series double beam UV-spectrophotometer between the wavelengths of 300 and $250 \mathrm{~nm}$, with a $1 \mathrm{~cm}$ path-length quartz cuvette. Using the information obtained from the HPLC, the spectra from furfural and HMF were subtracted from the sample spectrum by use of calibration curves of furfural and HMF at their characteristic maxima around $280 \mathrm{~nm}$. The lignin content was estimated using a calibration curve (slope 23.561) of the absorbance with respect to concentration of Indulin AT in ethylene glycol at about $280 \mathrm{~nm}$. The estimated detection limit of this method was

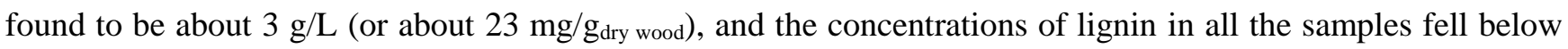
this limit.

\section{Results and discussion}

Preliminary testing showed that the addition of formic acid increased the hemicellulose hydrolysis to xylose and furfural (Fig. 1). It was also found that a liquid-to-wood-ratio ( $\mathrm{LtW})$ of 8 yielded a higher extraction level per unit mass than a $\mathrm{LtW}$ of $4\left(17 \mathrm{wt} \%\right.$ higher at $\left.150{ }^{\circ} \mathrm{C}\right)$; these values of $\mathrm{LtW}$ were chosen as they have been used for solid-liquid biomass reactions ( $\mathrm{Li}$ et al. 2016, Peleteiro et al. 2016, Watkins et al. 2015) . Additionally, the preliminary results showed that the xylose extraction could be improved at temperatures below $150{ }^{\circ} \mathrm{C}$ and concentrations of formic acid above $4.85 \mathrm{wt} \%$. Moreover, it was found that lower temperatures favored a higher extraction yield ratio. Three temperatures were ultimately chosen for the experimentation: a 'high' temperature of $170{ }^{\circ} \mathrm{C}$ as it has been used previously in water extraction (Li et al. 2013), and two lower temperatures below 150 ${ }^{\circ} \mathrm{C}\left(130\right.$ and $\left.140{ }^{\circ} \mathrm{C}\right)$. To assess the effect of increased formic acid present in the reaction medium, concentrations of $7.24,14.52$, and $21.76 \mathrm{wt} \%$ with respect to the solvent mass were used. Additionally, experiments without added formic acid were carried out for comparison. 
The main advantages of formic acid aided hot water extraction over its uncatalyzed counterpart are the lower reaction temperature and shorter contact times which, in continuous process, would translate to smaller equipment. Due to the lower process temperature, lower pressure steam could be used at $130-140{ }^{\circ} \mathrm{C}\left(\mathrm{e} . \mathrm{g} .4 \mathrm{barg}, 151{ }^{\circ} \mathrm{C}\right)$ than at $170{ }^{\circ} \mathrm{C}$ (e.g. 10 barg, $184{ }^{\circ} \mathrm{C}$ ). Recovery of formic acid is well established in the industry, which would be arguably easier to achieve than neutralization or recovery when using sulfuric acid as catalyst.

\subsection{Xylose and furfural yields}

Fig. 2 shows the xylose and furfural yields as percentages of the total estimated moles of hemicellulose. The trend clearly indicates a remarkable increase in the xylose extraction at lower temperatures $\left(130,140{ }^{\circ} \mathrm{C}\right)$ with formic acid. However, this effect was less significant at higher concentrations of formic acid. The maximum xylose yield without added formic acid was $27 \mathrm{~mol} \%$ of the total hemicellulose at 3 hours reaction time and $170{ }^{\circ} \mathrm{C}$. At the lower temperatures the extraction yield remained below $3 \%$. On the other hand, when $7.24 \mathrm{wt} \%$ of formic acid was used, the xylose yield increased to a maximum of $54 \mathrm{~mol} \%$ at 2 hours reaction time and $140{ }^{\circ} \mathrm{C}$. At $170{ }^{\circ} \mathrm{C}$, the xylose yield decreased with time, likely due to dehydration of xylose into furfural and degradation of xylose into side-products (e.g. humines). Increasing the formic acid concentration to 14.52 and $21.76 \mathrm{wt} \%$ did not have any major effect, other than an apparent faster extraction at the lowest temperature $\left(130{ }^{\circ} \mathrm{C}\right)$ and a decrease in maximum xylose yield (47 mol\%). The shapes of the curves at $170{ }^{\circ} \mathrm{C}$ suggest that the xylose yield becomes increasingly time-sensitive as the concentration of acid increases. With the highest formic acid concentration (21.76 wt \%), the xylose yield decreases dramatically between 0.5 and 1 hour reaction times (46 to $22 \mathrm{~mol} \%$ ).

Furfural is obtained through the dehydration of xylose. The furfural yield varied significantly with respect to temperature and formic acid concentration, with furfural yield being favored by both longer times and higher acid concentrations. Without added formic acid, at $3 \mathrm{~h}$ reaction time and at the highest temperature $\left(170{ }^{\circ} \mathrm{C}\right)$ the yield of furfural was $20 \mathrm{~mol} \%$. At lower temperatures, the yield remained below $0.4 \mathrm{~mol} \%\left(140{ }^{\circ} \mathrm{C}\right)$ and $0.1 \mathrm{~mol} \%$ $\left(130{ }^{\circ} \mathrm{C}\right)$. With formic acid, the furfural yield increased at all temperatures, particularly at $170{ }^{\circ} \mathrm{C}$. The dehydration of xylose into furfural is likely favored at higher temperatures. In all cases, the lowest amount of furfural was 
obtained at the lowest temperature $\left(130{ }^{\circ} \mathrm{C}\right)$ and shortest reaction time $(0.5-1 \mathrm{~h})$. With formic acid at 14.52 and $21.76 \mathrm{wt} \%$, the trial runs at $170{ }^{\circ} \mathrm{C}$ showed a decrease in the furfural amount, likely due to the degradation and polymerization of furfural (Lamminpää et al. 2014).

\subsection{Xylose \& furfural combined yield}

Fig. 3 shows the total yield of hemicellulose products (xylose and furfural). Without formic acid, the lower temperatures yielded below 2 and 3 mol\% at 130 and $140{ }^{\circ} \mathrm{C}$ respectively. At $170{ }^{\circ} \mathrm{C}$, the maximum yield (47 mol\%) was achieved at the longest reaction time $(3 \mathrm{~h})$. With formic acid, a remarkable increase in the yield (particularly at 130 and $140{ }^{\circ} \mathrm{C}$ ) can be seen in all cases with respect to the case without formic acid. However, the maximum yield achieved (70 mol\%) was with the highest concentration of formic acid (21.76 wt $\%)$ at the highest temperature $\left(170{ }^{\circ} \mathrm{C}\right)$ for the shortest reaction time $(0.5 \mathrm{~h})$. With formic acid, the yield trend at the lower temperatures was to increase with time (particularly at $7.24 \mathrm{wt} \%$ of formic acid). In contrast, at $170{ }^{\circ} \mathrm{C}$, the yield decreased with time. This decrease in yield can be explained by the uncontrollable degradation of hemicellulose and its hydrolysis products at higher temperatures (i.e. $170{ }^{\circ} \mathrm{C}$ ). Xylose dehydrates to furfural and can polymerize to water insoluble humins. Furfural, in turn, can also degrade to humins. The HPLC chromatograms showed the presence of possible oligomers (such as cellobiose) and higher order sugars (polysaccharides). It is possible that these higher order polysaccharides are the unreacted hemicelluloses in the form of glucuronoxylan, as it is typically the dominant hemicellulose in birch (Testova et al. 2009). Nevertheless, the chromatogram peaks were significantly smaller than the main compounds which would suggest a relatively small amount of these oligomers and sugars. The data at $170{ }^{\circ} \mathrm{C}$ suggests that the local maximum of hemicellulose extraction could be below the $0.5 \mathrm{~h}$ reaction time and thus a very short reaction time $(<0.5 \mathrm{~h})$ could suffice to reach this maximum.

\subsection{Glucose \& HMF yield}

The cellulose yield in the liquid product was desired as low as possible. An indicator of the cellulose extraction yield was the combined amount of glucose and HMF (hydroxymethylfurfural). HMF is obtained by the acid-hydrolysis of cellulose and subsequent dehydration of glucose. Without added formic acid, the lowest yield 
of glucose + HMF was obtained at the lowest times at all temperatures, as seen from Fig. 4. The addition and increase of formic acid concentration yielded a higher amount of glucose and HMF. This trend was more drastic at $170{ }^{\circ} \mathrm{C}$ than at the lower temperatures. At $130{ }^{\circ} \mathrm{C}$, the glucose $+\mathrm{HMF}$ yield remained below 5 mol $\%$ of the total cellulose content for all acid concentrations. At $140{ }^{\circ} \mathrm{C}$, the yield remained below $7 \mathrm{~mol} \%$. At $170{ }^{\circ} \mathrm{C}$, the yield at $3 \mathrm{~h}$ reaction time was the highest, with yields of $12 \%$ (7.24 wt $\% \mathrm{HCOOH}), 15 \mathrm{~mol} \%(14.52 \mathrm{wt} \% \mathrm{HCOOH})$, and $17 \mathrm{~mol} \%(21.76 \mathrm{wt} \% \mathrm{HCOOH})$.

\subsection{Extraction yield ratio}

The extraction yield ratio (EYR) was calculated as the ratio of the combined yield of xylose and furfural to the combined yield of glucose and HMF. Thus, not only was a high yield of extraction desired, but also a high extraction yield ratio. When no formic acid was added, the EYR increased with reaction time at 130 and $140{ }^{\circ} \mathrm{C}$, whereas at $170{ }^{\circ} \mathrm{C}$ it decreased. In the runs with added formic acid, the lowest temperature $\left(130{ }^{\circ} \mathrm{C}\right)$ exhibited higher maximum EYR than at 140 and $170{ }^{\circ} \mathrm{C}$. The maximum EYR without added formic acid was obtained at 1 h reaction time and $170{ }^{\circ} \mathrm{C}(14)$. For the lower temperatures, the extraction yield ratio remained below 3 . With $7.34 \mathrm{wt} \%$ formic acid in the reaction medium, the highest EYR (14) was achieved at $2 \mathrm{~h}$ at $130{ }^{\circ} \mathrm{C}$, as well as at 1 $\mathrm{h}$ at $140{ }^{\circ} \mathrm{C}$. The extraction yield ratio at the earliest sampling point $(0.5 \mathrm{~h})$ at $170{ }^{\circ} \mathrm{C}$ for the cases with formic acid, was smaller with increasing formic acid concentration: 9 (7.24 wt\% HCOOH), 8 (14.52 wt\%), and 7 (21.76 wt\%). Using lower temperature kept the extraction yield ratio in the product relatively high. The temperature-dependent behavior of the EYR could be linked to the activation energies of the hydrolysis of cellulose and hemicellulose. If the activation energy of the hydrolysis of cellulose were larger than the activation energy of the hydrolysis of hemicellulose, then lower temperatures would favor hemicellulose products, which is the case in this study. Additionally, as the formic acid concentration increased, the reaction favored the cellulose extraction. This may have been caused by the rapid extraction of hemicellulose, leaving the cellulose more vulnerable to extraction in a shorter time. It is possible that a higher maximum EYR could be found at times below $1 \mathrm{~h}$ and $140{ }^{\circ} \mathrm{C}$. 
Formic-acid-aided hot water extraction could find its major utility in pretreatment of lignocellulosic feedstock before delignification and cellulose processing. The possible mild process conditions would allow the cellulose and lignin to remain mostly in the solid residue, while most of the hemicellulose with traces of cellulose and lignin would be separated into the soluble phase.

\section{Conclusions}

Hemicellulose was extracted from birch sawdust by hot water extraction. Formic acid increased the extraction of hemicellulose at all temperatures $\left(130,140,170{ }^{\circ} \mathrm{C}\right)$. A mild $\left(130{ }^{\circ} \mathrm{C}\right)$ and long $(2 \mathrm{~h})$ treatment proved beneficial for xylose yield. A higher hemicellulose yield with higher proportion of furfural was possible at $170{ }^{\circ} \mathrm{C}$ and $0.5 \mathrm{~h}$. Formic-acid-aided hot water extraction is a feasible technique for hemicellulose extraction from wood, keeping the cellulose degradation low. The solid product retains most of its cellulose, with decreased hemicellulose content. This solid product can be delignified, leaving a cellulose-rich, low-hemicellulose, low-lignin product with high added value.

\section{Acknowledgements}

We would like to thank Dr. Tero Tuuttila from the Kokkola University Consortium Chydenius (University of Jyväskylä) for his work in the compositional analysis of the birch sawdust.

This work was carried out thanks to funding from ERDF project PreBio (decision nr EURA 2014/162/09 0201 01/2014/PPL)

\section{References}

1. Budzinski M \& Nitzsche R. (2016) Comparative economic and environmental assessment of four beech wood based biorefinery concepts. Bioresour Technol 216: 613-621.

2. Dutta SK \& Chakraborty S. (2015) Kinetic analysis of two-phase enzymatic hydrolysis of hemicellulose of xylan type. Bioresour Technol 198: 642-650.

3. Ehrman T. (1996) Determination of acid-soluble lignin in biomass. National Renewable Energy Laboratory, Technical Report NREL-LAP-004, Golden, CO . 
4. Hatfield R \& Fukushima RS. (2005) Can Lignin Be Accurately Measured? Crop Science 45(3): 832-839.

5. Hu X, Lievens C \& Li C. (2012) Acid-catalyzed conversion of xylose in methanol-rich medium as part of biorefinery. ChemSusChem 5(8): 1427-1434.

6. Krogell J, Eränen K, Granholm K, Pranovich A \& Willför S. (2014) High-temperature pH measuring during hot-water extraction of hemicelluloses from wood. Industrial Crops and Products 61: 9-15.

7. Krogell J, Korotkova E, Eränen K, Pranovich A, Salmi T, Murzin D \& Willför S. (2013) Intensification of hemicellulose hot-water extraction from spruce wood in a batch extractor - Effects of wood particle size. Bioresour Technol 143: 212-220.

8. Kupiainen L, Ahola J \& Tanskanen J. (2012) Hydrolysis of organosolv wheat pulp in formic acid at high temperature for glucose production. Bioresour Technol 116: 29-35.

9. Kupiainen L, Ahola J \& Tanskanen J. (2014) Kinetics of Formic Acid-catalyzed Cellulose Hydrolysis. BioResources 9(2): 2645-2658.

10. Lamminpää K, Ahola J \& Tanskanen J. (2014) Kinetics of furfural destruction in a formic acid medium. RSC Adv 4(104): 60243-60248.

11. Lamminpää K, Ahola J \& Tanskanen J. (2012) Kinetics of Xylose Dehydration into Furfural in Formic Acid. Ind Eng Chem Res 51(18): 6297-6303.

12. Li J, Zhang C, Hu H \& Chai X. (2016) Effect of shortening kraft pulping integrated with extended oxygen delignification on biorefinery process performance of eucalyptus. Bioresour Technol 202: 119-124.

13. Li M, Sun S, Xu F \& Sun R. (2012) Formic acid based organosolv pulping of bamboo (Phyllostachys acuta): Comparative characterization of the dissolved lignins with milled wood lignin. Chem Eng J 179: 80-89.

14. Li Z, Qin M, Xu C \& Chen X. (2013) Hot Water Extraction of Hemicelluloses from Aspen Wood Chips of Different Sizes. BioResources 8(4).

15. Liu X, Lu M, Ai N, Yu F \& Ji J. (2012) Kinetic model analysis of dilute sulfuric acid-catalyzed hemicellulose hydrolysis in sweet sorghum bagasse for xylose production. Industrial Crops and Products 38: 81-86.

16. Maurya DP, Singla A \& Negi S. (2015) An overview of key pretreatment processes for biological conversion of lignocellulosic biomass to bioethanol. 3 Biotech 5(5): 597-609.

17. Peleteiro S, Santos V, Garrote G \& Parajó JC. (2016) Furfural production from Eucalyptus wood using an Acidic Ionic Liquid. Carbohydr Polym 146: 20-25.

18. Rissanen JV, Murzin DY, Salmi T \& Grénman H. (2016) Aqueous extraction of hemicelluloses from spruce - From hot to warm. Bioresour Technol 199: 279-282.

19. Rowell R, Pettersen JS, Han JS \& Rowell MA. (2005) Cell Wall Chemistry. In: Rowell RM (ed) Handbook of Wood Chemistry and Wood Composites. Boca Raton, USA: CRC press: 35-74. 
20. Sahin HT \& Young RA. (2008) Auto-catalyzed acetic acid pulping of jute. Industrial Crops and Products 28(1): 24-28.

21. Scheller HV \& Ulvskov P. (2010) Hemicelluloses. Annu Rev Plant Biol 61(1): 263-289.

22. Sluiter A, Hames B, Ruiz R, Scarlata C, Sluiter J \& Templeton D. (2008a) Determination of ash in biomass. Laboratory Analytical Procedure (LAP). NREL, Golden, CO .

23. Sluiter A, Ruiz R, Scarlata C, Sluiter J \& Templeton D. (2008b) Determination of extractives in biomass (NREL/TP-510-42619). National Renewable Energy Laboratory, Golden .

24. Song T, Pranovich A \& Holmbom B. (2012) Hot-water extraction of ground spruce wood of different particle size. BioResources 7(3).

25. Styarini D, Risanto L, Aristiawan Y \& Sudiyani Y. (2012) Comparison of Two Analytical Methods for Compositional Analysis of Lignocellulosic Biomass for Bioethanol Production. Int J Environ Bioener 3(2): 88-97.

26. TAPPI T 280 pm-99. (1999) Acetone Extractives of Wood and Pulp, Test Method T 280 pm-99.

27. Tappi T203 cm-99. (2009) Alpha-, beta- and gamma-cellulose in pulp, Test Method T $203 \mathrm{~cm}-09$.

28. Testova L, Vilonen K, Pynnonen H, Tenkanen M \& Sixta H. (2009) Isolation of hemicelluloses from birch wood: distribution of wood components and preliminary trials in dehydration of hemicelluloses. Lezinger Berichte (87): 58-65.

29. Tunc MS, Chheda J, van der Heide E, Morris J \& van Heiningen A. (2014) Pretreatment of hardwood chips via autohydrolysis supported by acetic and formic acid. Holzforschung 68(4): 401-409.

30. Tunc MS \& van Heiningen A. (2008) Hemicellulose Extraction of Mixed Southern Hardwood with Water at $150{ }^{\circ} \mathrm{C}$ : Effect of Time. Industrial \& Engineering Chemistry Research 47(18): 7031-7037.

31. Wang W, Ren J, Li H, Deng A \& Sun R. (2015) Direct transformation of xylan-type hemicelluloses to furfural via $\mathrm{SnCl} 4$ catalysts in aqueous and biphasic systems. Bioresour Technol 183: 188-194.

32. Watkins D, Nuruddin M, Hosur M, Tcherbi-Narteh A \& Jeelani S. (2015) Extraction and characterization of lignin from different biomass resources. Journal of Materials Research and Technology 4(1): 26-32.

33. Xu J, Thomsen MH \& Thomsen AB. (2009) Pretreatment on corn stover with low concentration of formic acid. Journal of microbiology and biotechnology 19(8): 845-850.

34. Xu Y, Li K \& Zhang M. (2007) Lignin precipitation on the pulp fibers in the ethanol-based organosolv pulping. Colloids Surf Physicochem Eng Aspects 301(1-3): 255-263.

35. Yadav M, Mishra DK \& Hwang J. (2012) Catalytic hydrogenation of xylose to xylitol using ruthenium catalyst on $\mathrm{NiO}$ modified TiO2 support. Applied Catalysis A: General 425-426: 110-116.

36. Yokoyama T, Kadla JF \& Chang H. (2002) Microanalytical method for the characterization of fiber components and morphology of woody plants. Journal of agricultural and food chemistry 50(5): 1040-1044. 
37. Zhang W, Du B \& Qin Z. (2014) Catalytic effect of water, formic acid, or sulfuric acid on the reaction of formaldehyde with $\mathrm{OH}$ radicals. The journal of physical chemistry. A 118(26): 4797. 


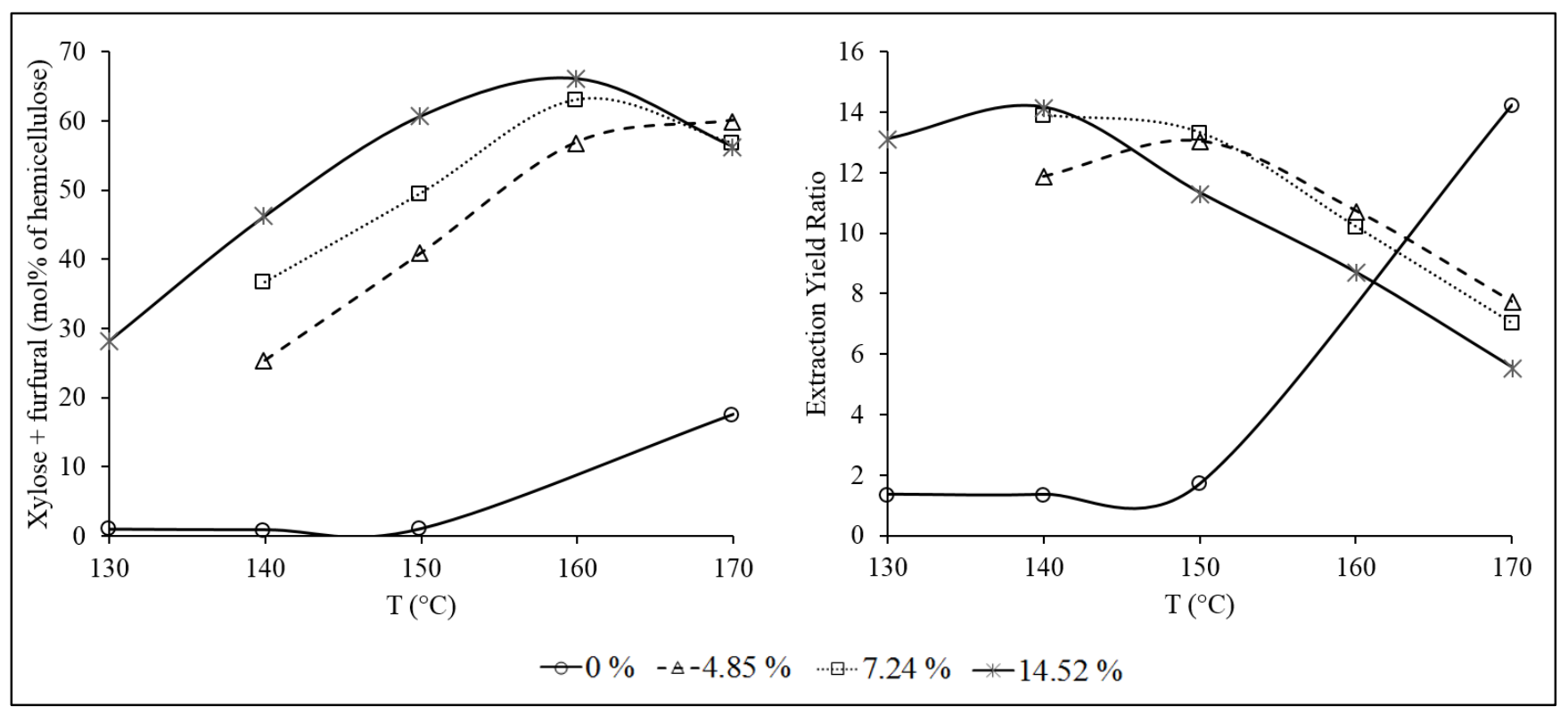

Fig. 1. Preliminary experiments. All runs were carried out for 1 hour at a LtW of 8 . Percentages in legend are wt\% of formic acid 


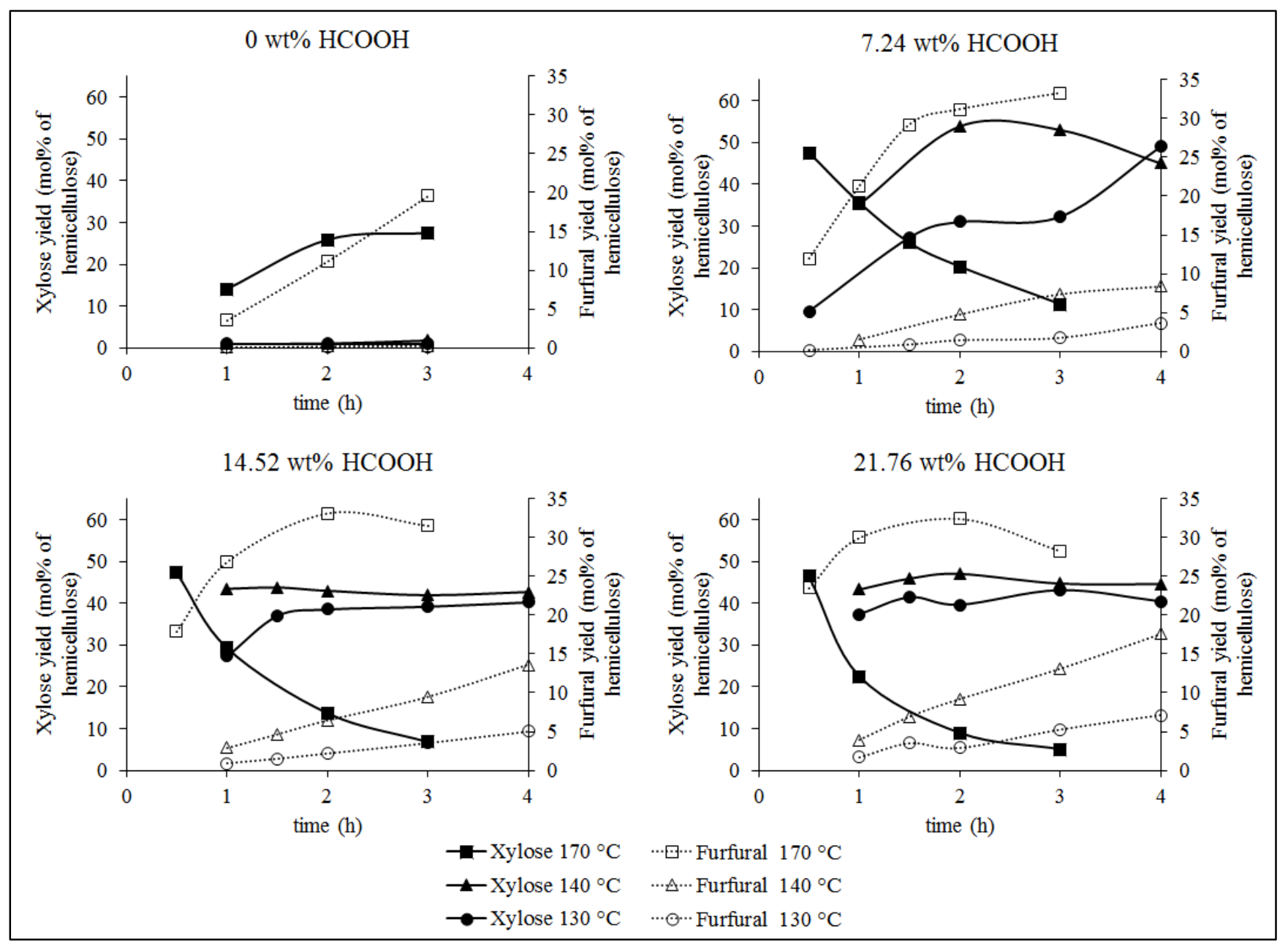

Fig. 2. Xylose and furfural yields as mole percentages of total hemicellulose. 


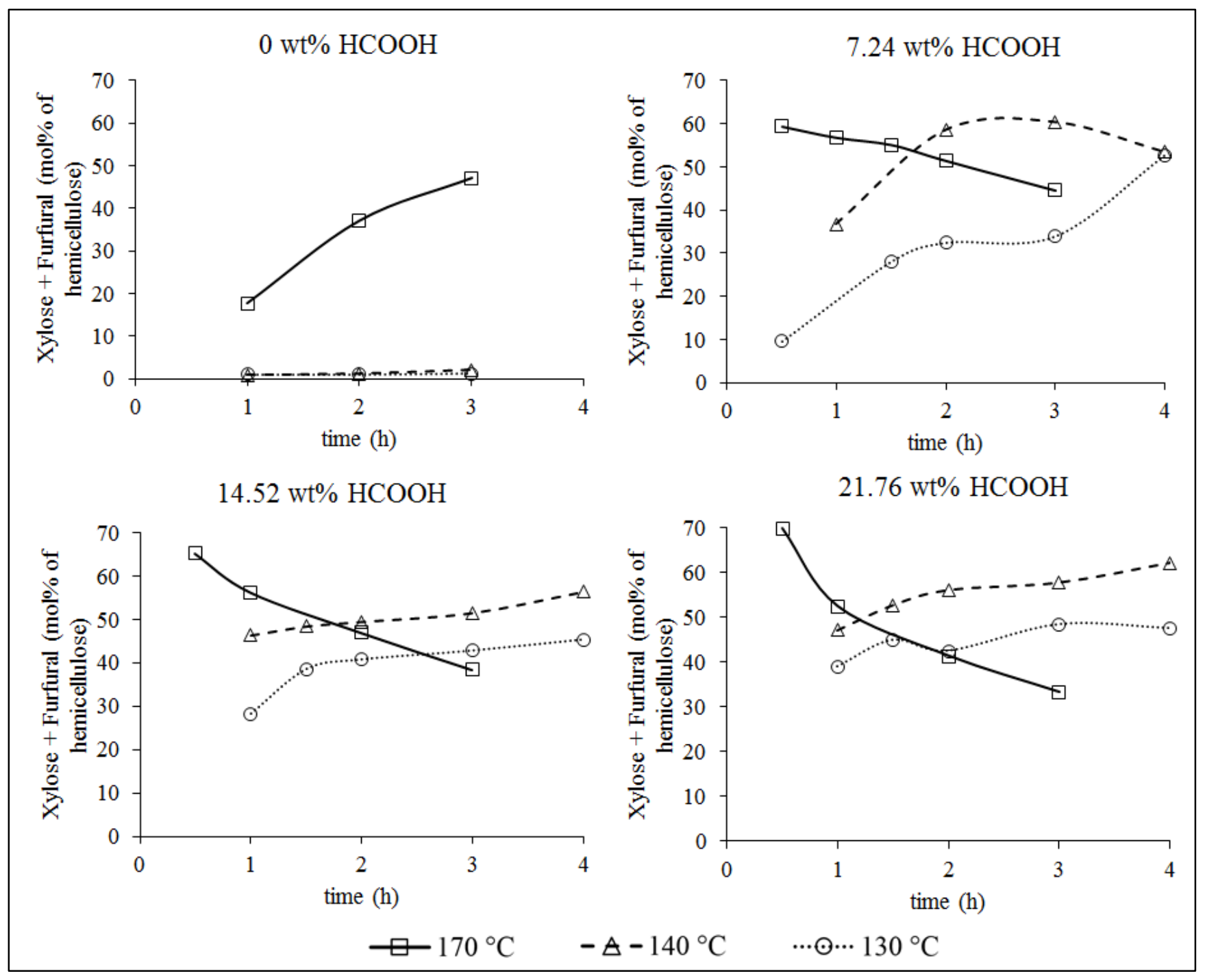

Fig. 3. Xylose and furfural combined yield as a mole percentage of total hemicellulose 


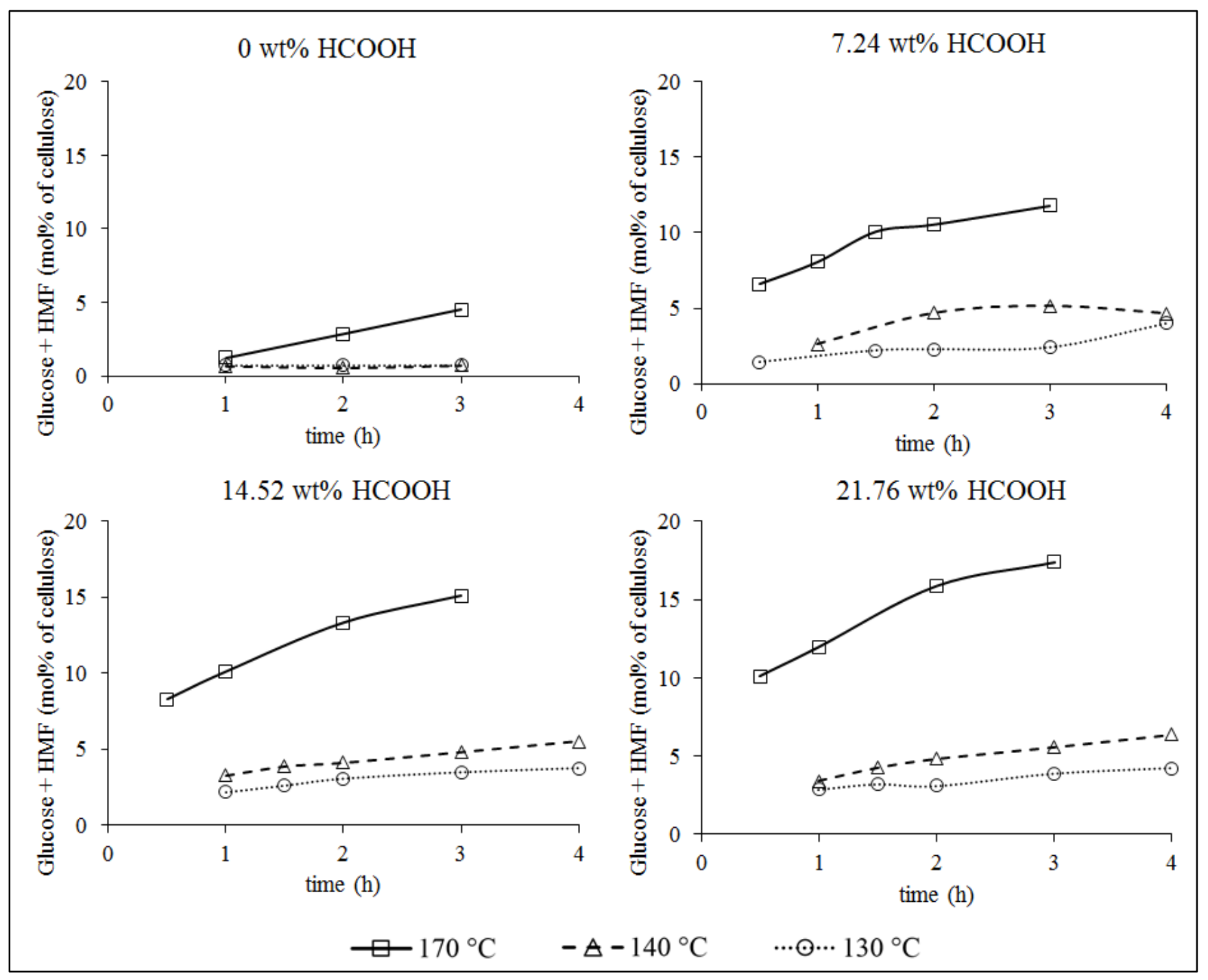

Fig. 4. Glucose and HMF combined yield as a mole percentage of total cellulose. 


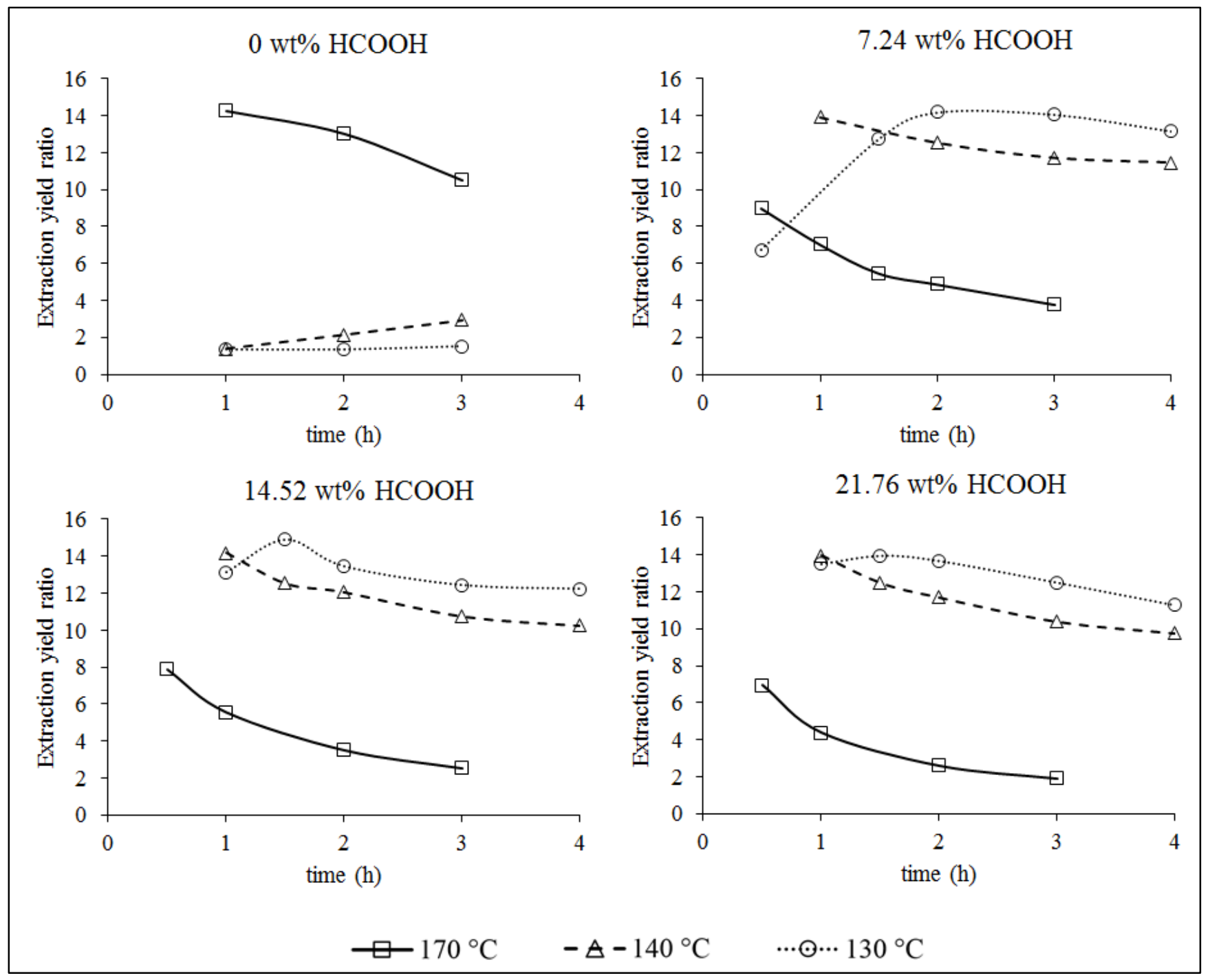

Fig. 5. Extraction yield ratio ([Xylose and Furfural combined yield] / [Glucose and HMF combined yield]). 